\title{
An Evolutionary Catch-up Strategy of Innovation: Knowledge Transfer of Chinese Hi-tech Multinationals Through Firm-University Cooperation
}

\author{
Guangyan Liu \\ Université Libre de Bruxelles, SBS-EM, iCite, Brussels, Belgium \\ Yingli Chen \\ Université Libre de Bruxelles, SBS-EM, CEB, Brussels, Belgium
}

\begin{abstract}
Chinese hi-tech multinationals strengthen their technological competitiveness in their internationalization process. Their strategic emphasis on cooperation with academic institutes to develop professional knowledge is an important yet underexplored issue in the extant literature. Based on the comparison between a pair of hi-tech companies-HUAWEI from China and CISCO from the US, this study analyzes the process of technological evolution of the former during 1998-2014, which has already become one of strategic solutions for Chinese multinationals (CMNE) to catch up with traditional counterparts in technological field. This study contributes to the present theory of CMNE by disclosing the Firm-University Cooperation (FUC) strategy, as well as its significance and implications for later-comer's catch-up trajectory in international business.
\end{abstract}

Keywords: multinationals, catch-up strategy, Firm-University Cooperation

\section{Introduction}

The emergence of Chinese multinationals in international business arena has attracted the attention of scholars and managers. More and more people become curious about how CMNE grow into international players and even industrial leaders in decades. To address this curiosity, a variety of theoretical frameworks for CMNE as well as counterparts from other emerging economies have been developed. Among them, catch-up strategy has been explained by different scholars (Deng, 2009; Luo \& Tung, 2007; Mathews, 2002). Supporters of this school argue that CMNE obtain advanced technology, brands, know-hows, distribution channels, and other strategic resources overseas to strengthen their competitiveness and to offset their disadvantages in these fields. The recent empirical literature has further explained their strategy from the perspective of international M\&A (Luo, Xue, \& Han, 2010; Peng, 2012). Yet, CMNE differ from traditional MNE from developed countries in resources integration with regard to their different competitive position and management

Guangyan Liu, Ph.D., researcher, Solvay Brussels School of Economics and Management (SBS-EM), the International Centre for Innovation, Technology and Education Studies (iCite), Université Libre de Bruxelles, Brussels, Belgium.

Yingli Chen, Ph.D., researcher, Solvay Brussels School of Economics and Management (SBS-EM), Centre Emile Bernheim (CEB), Université Libre de Bruxelles, Brussels, Belgium.

Correspondence concerning this article should be addressed to Yingli Chen, S. H4.126, ULB, Av. Franklin Rooseveltlaan 50, CP114/03, 1050 Brussels, Belgium. 
philosophy. This is proved in the study of FUC based on patent data (Hong \& Su, 2013). How do CMNE in hi-tech industry enhance their capability in international context while as they confront with fierce rivalry from traditional MNE? There are few studies so far to answer this question based on in-depth analysis.

This paper is to address this issue through comparing the leading Chinese telecommunication company HUAWEI with CISCO and analyze individual academic outputs and evolution cooperating with universities. The study is formulated in three steps. First, collecting HUAWEI and CISCO's data of public publications from 1998 to 2014 when HUAWEI started building links with academic institutes. Second, the research conducts in-depth comparison (Patton, 2005) between this pair of samples to explore relative changes each other. Third, combining respective data of publication number with market share together. Chronical divergence of academic outputs between HUAWEI and CISCO through FUC is demonstrated. This study attributes to extant research CMNE by disclosing how a Chinese hi-tech enterprise catches up with and then surpasses its competitor from advanced economy. Furthermore, the explanation provides researchers with a broader perspective to understand CMNE's catch-up strategy.

\section{Literature Review}

\section{Catch-up Strategy}

The study on how CMNE compete with traditional MNE in business arena focuses on their competitive advantages and disadvantages. In hi-tech industry, diverse disadvantages like technological insufficiency, lack of international management knowhow, talents, and even strategic assets restrict the development of emerging MNE (Awate, Larsen, \& Mudambi, 2012; Kedia, Gaffney, \& Clampit, 2012; Luo \& Rui, 2009; Madhok \& Keyhani, 2012). In order to grow into a strong international competitor or even industrial leader, it is necessary to find a solution to offset the weaknesses. This thought is called "corner overtaking” in slang Chinese. Catch-up strategy, as a normal theory has attracted scholar's attention in these years. It represents exactly one of the solutions both the scholar and manager looking for. This argument is based on the ability of the firm to absorb the leveraged resources (Mathews, 2002). At the same time, emerging MNE possess their own advantages in some other aspects (Awate et al., 2012; Gaffney, Cooper, Kedia, \& Clampit, 2014). For example, they usually root in large-size domestic market and enjoy stable customer basis. That means they would have adequate financial resource. Although their home market is believed as institution void (Pillania, 2009), they exploit their specific know-how in the market and thus expand their business in other emerging economies, who are experiencing higher economic growth than advanced countries. To address the issue to increase advantages and offset disadvantages, they are engaging in "inward" internationalization by means of original equipment manufacturer (OEM) and joint venture partnerships, and "outward” internationalization by means of acquisition and organic expansion abroad (Child \& Rodrigues, 2005).

\section{Firm-University Cooperation (FUC)}

FUC is popular for traditional MNE and thus extant empirical studies pay more attention to advanced economies, where there are rich academic resources. In particular, large firms are more likely to be actively involved in industry science links than small and medium sized counterparts (Veugelers \& Cassiman, 2005). Firms with internal R\&D strategies more heavily weighted toward exploratory activities allocate a greater share of their R\&D resources to exploratory university research and develop deeper multifaceted relationships with their university research partners (Bercovitz \& Feldman, 2007). Regarding to the collaboration with universities, 
two types of agreements were distinguished: "science and technology-based” (Giuliani, Gorgoni, Günther, \& Rabellotti, 2014) and "learning-by-doing, by-using, and by interacting-based” (DUI) partnerships (González-Pernía, Parrilli, \& Peña-Legazkue, 2015). The research has proved that the two kinds of partnership are important for product and process innovation in both separate and combined ways. Furthermore, product innovation benefits more from the combination of DUI and STI partnerships and process innovation seems to be more closely linked to DUI-related partnerships undertaken by firms (González-Pernía et al., 2015). These results make sense of the potential role of FUC for technology seekers. More interestingly, companies with university linkages have lower R\&D expenses while having higher levels of innovative output (George, Zahra, \& Wood, 2002). It means a more efficient resource distribution mode to improve the competiveness. As one side of the partnership, managers manage to find ways to create links with academic institutes. The most outstanding factors for them are commitment, previous links, definition of objectives, and conflict (Mora-Valentin, Montoro-Sanchez, \& Guerras-Martin, 2004). With the development of CMNE, FUC has been utilized as a strategic solution to achieve intellectual resources. However, there are few studies to address this issue.

\section{Data Collection}

HUAWEI was founded in 1988 and her main revenue was from rural markets before 1997. However, HUAWEI expanded her market to China's major cities ${ }^{1}$ and put forward the wireless GSM solutions in 1997. HUAWEI began to entry the international market from 1995, but her international business made a breakthrough development until 1999. After that, HUAWEI has experienced a quick development. Therefore, the data collection of HUAWEI is within 1998-2014, and the same data period is used for CISCO.

All the data of publications written by one of the authors from HUAWEI and CISCO are gotten from WEB OF SCIENCE ${ }^{2}$ that includes co-publications with academic universities and research institutes and non-co-publications. The study uses "huawei" and "cisco" according to "address" 3 as the key words when searching publications written by one of the authors from HUAWEI and CISCO in WEB OF SCIENCE, through deleting invalid values and blank data, original data about publications of the two companies, 1,007 figures for HUAWEI and 1,370 for CISCO, is obtained finally. The transfer of knowledge would influence directly the competitiveness of a company then affect a company's strategy. The research therefore tries to check the whole condition of co-publications with universities of HUAWEI at first. Further, in order to choose the papers with top 150 universities in the world, the authors employ the list of 2014 Academic Ranking of World Universities (ARWU) ${ }^{4}$ released by the Center for World-Class Universities at Shanghai Jiao Tong University as the criteria to choose top universities, which is recognized as more academic than other rankings of universities. A survey on higher education published by the Economist in 2005 commented ARWU as "the most widely used annual ranking of the world's research universities”. Simon Margison, the Professor of Institute of Education in University of London, commented that one of the strengths of "the academically rigorous and globally inclusive ARWU” is “constantly tuning its rankings and invites open collaboration in that".

Regarding globalization of one enterprise, one of the main measurements is oversea market share. The oversea market share of HUAWEI and CISCO is handmade data. According to the annual fiscal report of

\footnotetext{
1 The data are from annual report of HUAWEI.

2 http://www. webofscience.com/.

3 The "address" records the information about the addresses of all authors in one paper in the database of WEB OF SCIENCE.

${ }^{4}$ http://www.shanghairanking.com/.
} 
HUAWEI and CISCO, and then computing their oversea market shares, the period of HUAWEI is 2003-2014, and CISCO is 2001-2014 ${ }^{5}$. The paper adopts in-depth comparison to analyze the ability of knowledge transfer of HUAWEI (Patton, 2005; Milena, Dainora, \& Alin, 2008). The paper makes the horizontal and chorological comparison on co-publications between HUAWE and CISCO.

\section{Data Description}

The study has three categories of data about HUAWEI and CISCO, co-publications, co-publications with universities, and oversea markets share. This section compares the co-publications of HUAWEI and CISCO at first, and then analyzes their co-publications with top 150 universities. In order to see the globalization of HUAWEI, the research finally studies the link between their oversea market shares and co-publications.

\section{Co-publications of HUAWEI and CISCO}

There are 1,007 papers with at least of one author is the employee of HUAWEI from 1998 to 2014. Among these papers, the number of co-publications is 542 and non-co-publications is 465, which make up $53.82 \%$ and $46.18 \%$ respectively. The authors find that over half of publications of HUAWEI are cooperated with universities during her period of expansion. It means that HUAWEI stresses importance of cooperation with academic institutes. She owns a large possibility and potentiality of knowledge transfer.

During the period between 1998 and 2014 (Figures 1 and 2), there are 1,370 papers with at least of one author is the staff of CISCO including 584 co-publications with academic universities while 786 papers are not co-publications. For CISCO, the percentage of co-publications is less than that of non-co-publications. Comparing HUAWEI and CISCO, the paper finds that although HUAWEI lost in the comparison of number of public publications, at the percentage of co-publications she gets an obvious win against CISCO. The strategy of FUC is utilized as a solution to attain intellectual resource by HUAWEI.

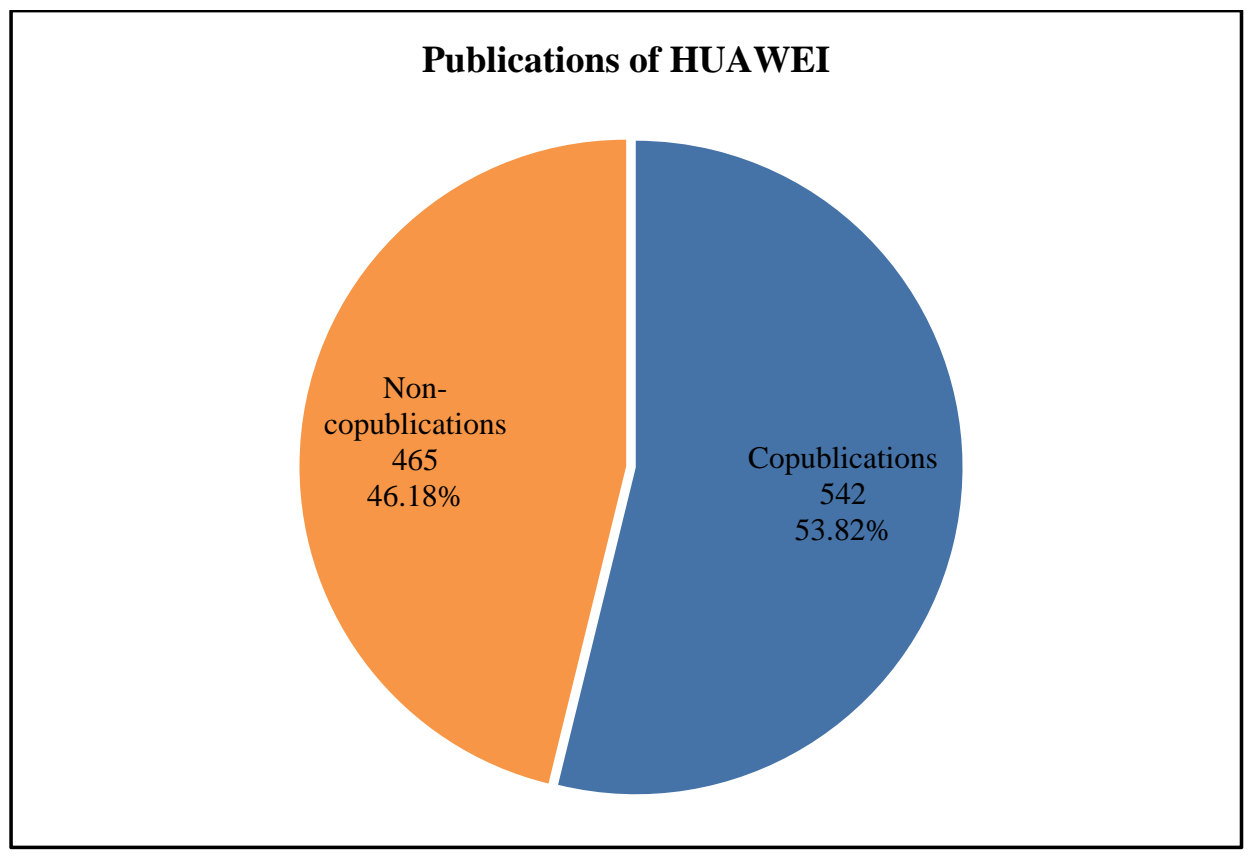

Figure 1. The number of all publications of HUAWEI 1998-2014.

\footnotetext{
${ }^{5}$ We do not get full fiscal data of HUAWEI and CISCO from 1998 to 2014 because of some limitation.
} 


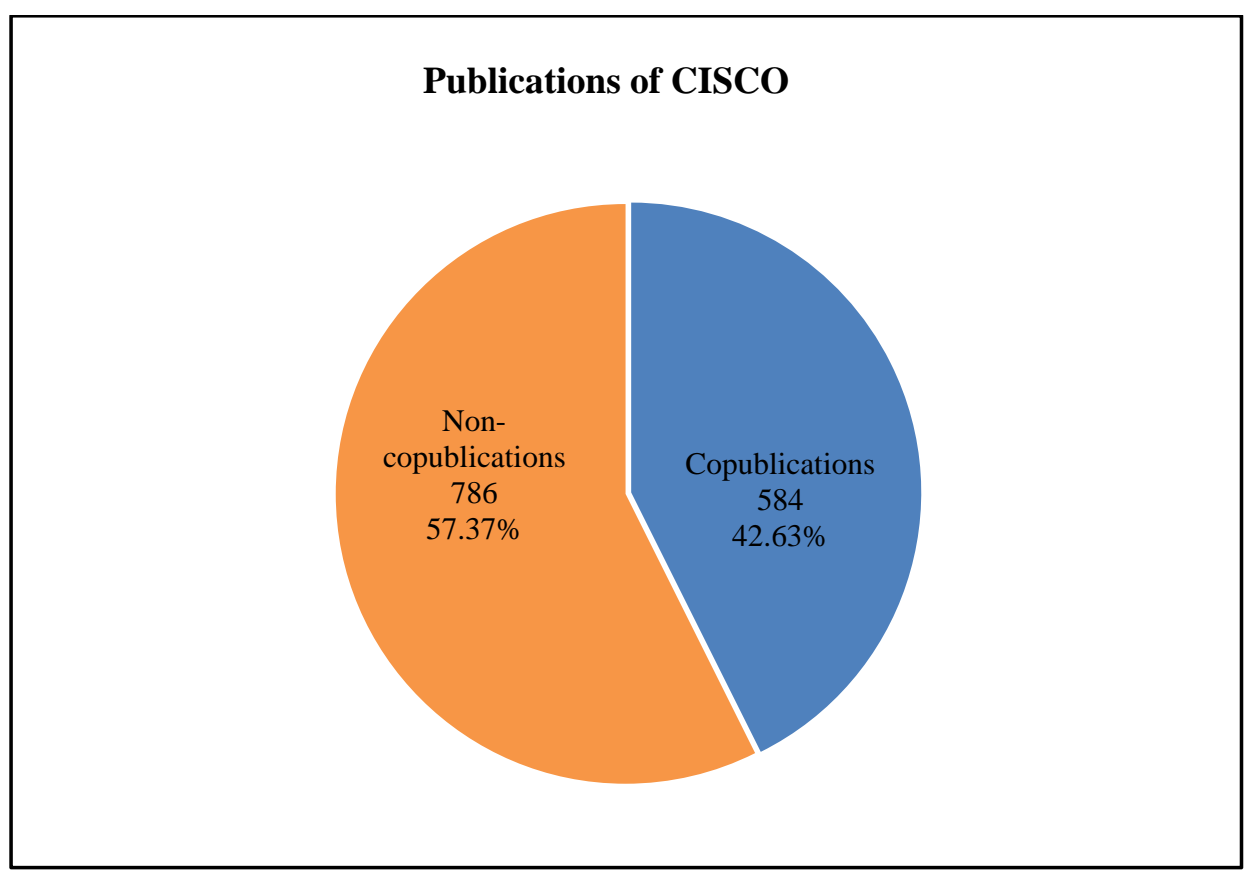

Figure 2. The number of all publications about CISCO 1998-2014.

\section{Co-publications With Top 150 Universities of HUAWEI and CISCO}

After matching the table of co-publications of HUAWEI and CISCO with the list of top 150 universities, the study gets the information of co-publications with top 150 universities of HUAWEI and CISCO. Top 100 universities are often adopted in the research, but there are no Chinese universities or institutes shown in the top 100 universities in AWRU, so this paper expands the range to top 150 universities.

Table 1

The Number of Co-publications With Universities of HUAWEI and CISCO

\begin{tabular}{lll}
\hline & All co-publications & Co-publications with top 150 universities \\
\hline \multirow{2}{*}{ HUAWEI } & 542 & 97 \\
\multirow{2}{*}{ CISCO } & 584 & $(17.90 \%)$ \\
& & 235 \\
\end{tabular}

As shown in Table 1, there is a little difference, HUAWEI is 542 and CISCO is 584, on the whole of number of co-publications. Yet, the number of co-publications with top 150 universities is with wide variations on HUAWEI and CISCO. CISCO has 235 cooperated papers occupying 40.24\% of all her co-publications, while HUAWEI just owns 97 co-publications accounting for $17.90 \%$. Although the number of co-publications of HUAWEI is much smaller, it's not a gulf exciting in the ability of knowledge transfer between HUAWEI and CISCO. There are 67 American universities but three Chinese universities in the list of top 150 universities. Companies prefer to collaborate with domestic universities or research institutes. This is because that it's convenient to cooperate with local academic organizations due to the lack of culture or language barrier (Adams, Black, Clemmons, \& Stephan, 2005).

HUAWEI emphasizes innovation and the ability of knowledge transfer. During last decades, HUAWEI strengthens the speed of knowledge transfer in order to make the company competitive. Further supports are given in Table 2. Table 2 lists the number of co-publications of HUAWEI and CISCO year by year. From 1998 
to 2014, there are totally 97 co-publications with top 150 universities of HUAWEI. The number of collaborated research papers with top 150 universities, however, is zero between 1998 and 2004. During the following five years, 2005 to 2009, HUAWEI's co-publications with top 150 universities begin to appear that the value is around two. At last five years, the value increases significantly from eight in 2010, following the continuous growth to 15 in 2011 and 18 in 2012 with a slight decrease to 16 in 2013, then arriving at the top of 32 in 2014. For CISCO, there are totally 235 co-publications with top 150 universities, and the average of number is about 14. The smallest number of collaborated research papers with top 150 universities is two in 1998, while the largest number is 30 in 2013. Between 2011 and 2014, the average of number of collaborated research papers with top 150 universities of CISCO is around 25. During the previous five years, 2006-2010, the average of number of cooperated papers is about 14 but with a "valley" of seven in the year of 2007. The average of number of joined hands research papers with top 150 universities of CISCO is around eight from 1998 to 2005. During this period, it emerges two summits of 11 in 2000 as well as 17 co-publications with top 150 universities in 2002. HUAWEI, a CMNE in hi-tech industry, enhances her capability in international context through FUC.

Table 2

The Number of Co-publications With Top 150 Universities of HUAWEI

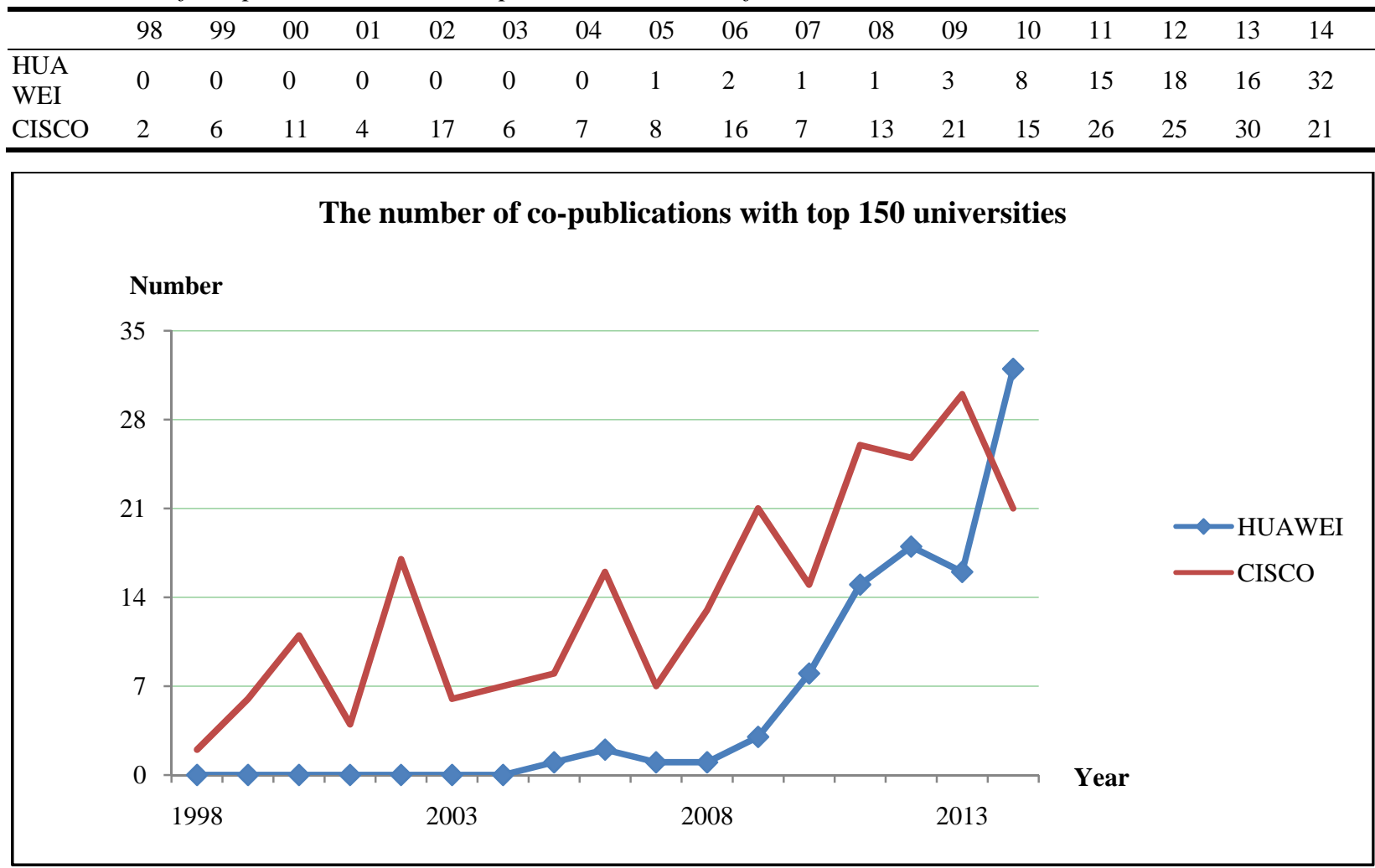

Figure 3. The co-publications with top 150 universities of HUAWEI and CISCO.

As seen from Figure 3, the number of co-publications with top 150 universities of CISCO is generally more than the figure of HUAWEI during the research period except 2014. However, the largest value of co-publications with top 150 universities of HUAWEI is bigger than that of CISCO, which the value of HUAWEI is 32 in 2014 and CISCO is 30 appeared in 2013. Both HUAWEI and CISCO, their smallest value of 
co-publications with top 150 universities are in 1998, CISCO is two and HUAWEI is zero. In the following six years, CISCO begins to rise the opportunities with top 150 universities, while HUAWEI is still zero. At that time, HUAWEI just begins to expand her market. The interesting thing is the trend of CISCO shows a growth with remarkably fluctuation and gets to the summit of 30 in 2013 then falls to 21 in 2014. On the contrary, HUAWEI shows a significant increase starting from 2009 and arrives at the top of 32 in 2014.

For CISCO, her co-publications with top 150 universities start from two in 1998 then rise three times in 1999 and about two times in 2000 but fall to four in 2001, yet grow over four times which the value is 17 in 2002. The number of co-publications with top 150 universities of CISCO decreases to around seven between 2003 and 2005. Before the value of CISCO falls to seven again in 2007, it grows to 16 in the previous year. With the development in the following two years, the number of co-publications of CISCO with top 150 universities is 21 in 2009, which the number is three times more than that of 2007. At the end of five years of the research period, CISCO still presents fluctuation, declining to 15 in 2010 and keeping around 27 from 2011 to 2013 then decreasing to 21 after arriving at the top value. Regarding HUAWEI, it shows a significant growth on the number of co-publications with top 150 universities. Before 2005, the value of HUAWEI is zero. There are not any collaborated research papers between HUAWEI and top 150 universities. Starting from 2005, HUAWEI begins to cooperate with top 150 universities of the world to do some research works, however, the figure still stays in lower level, i.e. one co-publication in 2005, 2007, and 2008, and two cooperated papers in 2006. After that, the number of co-publications with top 150 universities of HUAWEI begins to increase rapidly. From three co-publications in 2009, the number rises approximately two times in the next two years, arriving eight in 2010 and 15 in 2011. After a quick growth, the number of co-publications with top 150 universities of HUAWEI experiences an adjustment period. Before declining to 16 in 2013, it increases slightly to 18 in 2013. Then the number of co-publications of HUAWEI increases drastically to 32 in 2013 which is two times more than that in 2012.

For the differences between HUAWEI and CISCO on the co-publications with top 150 universities, the data of CISCO are generally bigger than that of HUAWEI during the research period. The smallest difference is two in 1998, while the biggest difference is 18 in 2009. The average of difference is about 8. Although the number of co-publications with top 150 universities of HUAWEI is generally less than that of CISCO, HUAWEI appears a sharp and obvious growth in period 1998-2014. As aforementioned research, companies are likely to cooperate with local universities because it would not have culture conflicts, language barriers, etc. (Cai \& Kohtamaki, 2014). HUAWEI and CISCO, one comes from China, and the other is from America. Among co-publications with top 150 universities, HUAWEI and CISCO collaborate with 21 same US universities and three same Chinese universities. During the same US universities, CISCO has 154 co-publications but HUAWEI has 52 co-publications, which CISCO is about three times more than HUAWEI. On the contrary, HUAWEI has 42 co-publications but CISCO has six co-publications with the same Chinese universities, which HUAWEI is approximately seven times more than CISCO.

Table 3

The Information of Co-publications With Same Top 150 Universities

\begin{tabular}{lll}
\hline & The same US universities (21) & The same China's universities (3) \\
\hline HUAWEI & 52 & 42 \\
CISCO & 154 & 6 \\
\hline
\end{tabular}


Through collaborating with universities, HUAWEI improves her advantages, and helps herself to carry out the strategy of globalization. From the analysis for co-publications of HUAWEI and CISCO, the result shows that multinational companies have a quite cooperative relationship with universities especially domestic academic organizations. The high-tech firm hopes to employ FUC, knowledge transformation, to influence the innovation, competitiveness of companies, and then affect directly development of companies.

\section{Oversea Markets Share of HUAWEI and CISCO}

As a rising star in communication industry, co-publications are a part of catch-up strategy of HUAWEI. In this part, the research compares the oversea markets share of HUAWEI and CISCO to check the international expansion of HUAWEI. The collected financial data of HUAWEI is within 2003-2014, and CISCO is 2001-2014. The paper keeps the period of their oversea markets shares the same-2003-2014 in order to ensure the consistency of results.

Table 4

Oversea Market Share of HUAWEI and CISCO

\begin{tabular}{|c|c|c|c|c|c|c|c|c|c|c|c|c|}
\hline & 03 & 04 & 05 & 06 & 07 & 08 & 09 & 10 & 11 & 12 & 13 & 14 \\
\hline HUAWEI & 0.28 & 0.41 & 0.58 & 0.65 & 0.72 & 0.75 & 0.6 & 0.65 & 0.67 & 0.68 & 0.65 & 0.62 \\
\hline CISCO & 0.44 & 0.45 & 0.46 & 0.45 & 0.45 & 0.46 & 0.46 & 0.46 & 0.42 & 0.42 & 0.41 & 0.41 \\
\hline
\end{tabular}

As shown in Table 4, the average of oversea market share of HUAWEI is about $61 \%$ which increases at the first of stage and then falls a little at the second stage. In the year of 2003, the oversea markets share is only $28 \%$, but it rises to $41 \%$ in 2004 . In the following four years, the oversea markets share of HUAWEI still increases, rising to 58\% and $65 \%$ in 2005 and 2006, and then arriving at the top of $75 \%$ in 2008 . The value drops to $60 \%$ in 2009, after that, it grows again over $65 \%$ from 2010 to 2013. After 2004, the share of oversea markets of HUAWEI begins to be more than 55\%. It means that the main revenue for HUAWEI is not from domestic market but oversea markets. During recent years, the share of oversea market of HUAWEI stays over $62 \%$. The oversea markets share of CISCO is stable with average value is $44 \%$ from 2001 to 2014. For the oversea markets share of CISCO, the smallest value is $41 \%$ in 2013 and 2014, but the largest value is $46 \%$ in the year of 2005, 2008, 2009, and 2010. The difference of the biggest value and smallest value is only 5\%. Her oversea markets share is never over 50\% during the research period. It exhibits that CISCO is a mature hi-tech company and stays in the stable period of her business life cycle.

CISCO displays a considerably steady trend at her oversea markets share. The figure is around $44 \%$ (Figure 4). Compared with recent four years, her oversea markets share in prior years is a bit higher which the value is about $45 \%$. CISCO is in the stable period of the company life cycle, and remains her share in the oversea markets. However, HUAWEI appears an obvious change on her oversea market share. Overall, it shows an "M" shape. The smallest value of oversea markets share is $28 \%$ in 2003 , while the largest figure is $75 \%$ in 2008. Before dropping to $60 \%$ in 2009, it remains an apparent increasing trend. After 2009, although the oversea markets share of HUAWEI rises to 68\% in 2012 then falls to 62\% in 2014, it keeps a level at about $66 \%$. It shows that HUAWEI is experiencing a growth period with regard to the company life cycle. The oversea markets share of CISCO stays at a stable level for a long period, but the number of her co-publications with universities shows a fluctuation with slight growth. On the contrary, HUAWEI has experienced an apparent growth in her oversea markets before 2009 and then begins to keep a steady development in her 
oversea markets. The number of co-publications of HUAWEI, whatever co-publications with top 150 universities or others, is still increasing. It means that FUC as one way of knowledge transformation helps HUAWEI implement the catch-up strategy and achieve international expansion. HUAWEI, from an ordinary Chinese company to a leading CMNE, obtains advanced technology, brands, know-hows, and other strategic resources overseas to strengthen her competitiveness.

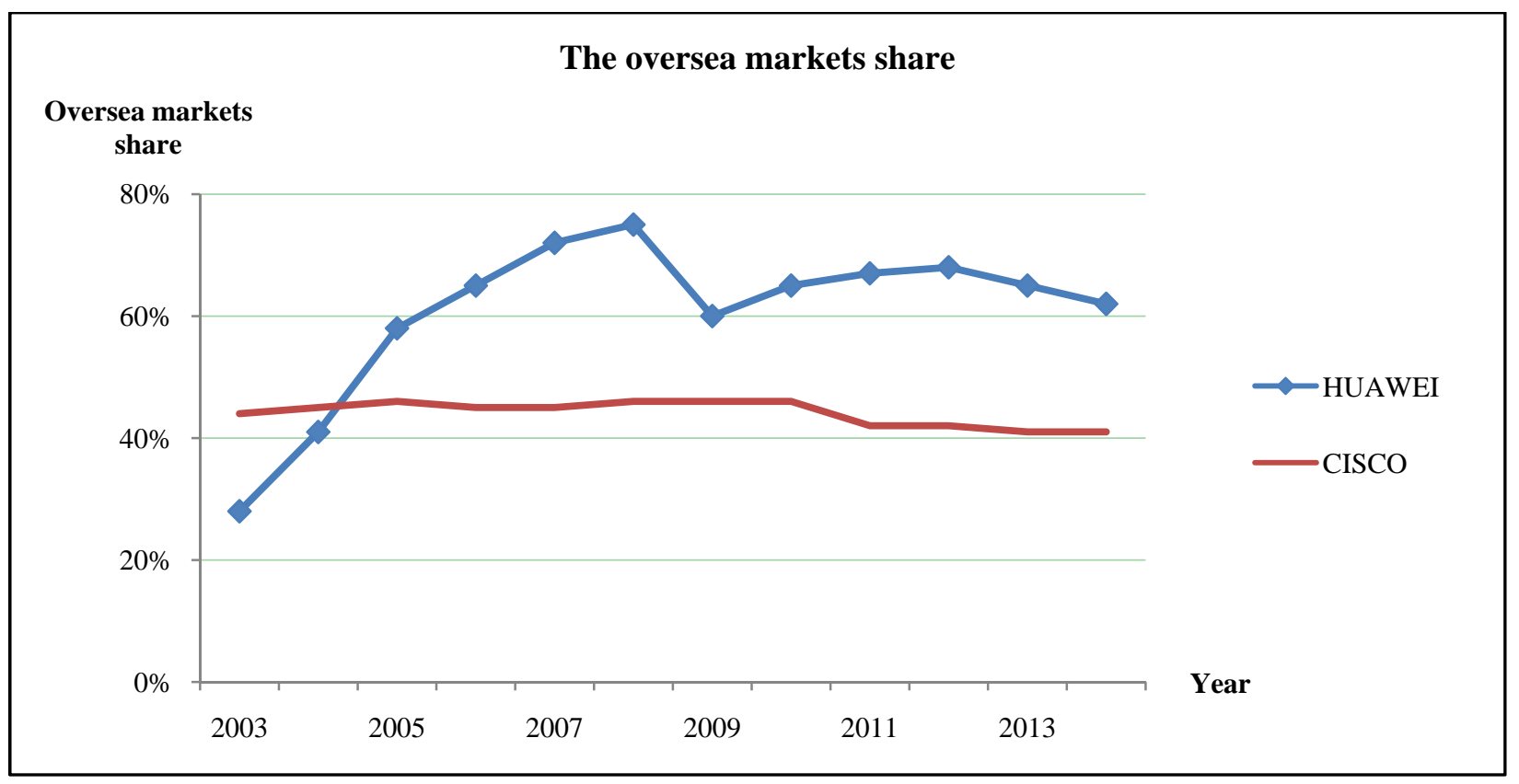

Figure 4. The comparison of oversea markets share between HUAWEI and CISCO.

\section{Conclusions}

The paper conducted a comparative analysis of academic co-publications between HUAWEI and CISCO. The former's strategic evolution of knowledge creation and transfer through FUC has contributed more and to its own technologic innovation over time. HUAWEI has become a leading company in telecommunication industry from an imitator and follower. This crucial transformation has led to gains of publications. This process exhibits the strategic role of FUC for the Chinese hi-tech company. However, it should not be ignored that HUAWEI's continuous cooperation with universities is based on its flexible organization arrangement and dominant position in domestic market, which means active academic involvement and plenty of inputs supported by lucrative market. The type of trajectory of growth is so representative for Chinese hi-tech companies that its competitor ZTE follows similar strategy to strengthen its competitiveness. HUAWEI's catch-up strategy compared with CISCO produces significant capacity by more academic outputs than the latter. The routine of HUAWEI management demonstrates the contradiction between centralized corporation system and dynamic innovation framework has been somewhat exaggerated. Concerning with further study, it is necessary to identify the different types of collaboration leading to different types of innovation in Chinese enterprises. Although the authors have already elaborated the implications of FUC for HUAWEI's catch-up strategy in this paper, the more extensive dimension of FUC for more CMNE from diverse industries should be investigated in future. 


\section{References}

Adams, J. D., Black, G. C., Clemmons, J. R., \& Stephan, P. E. (2005). Scientific teams and institutional collaborations: Evidence from US universities, 1981-1999. Research Policy, 34(3), 259-285.

Awate, S., Larsen, M. M., \& Mudambi, R. (2012). EMNE catch-up strategies in the wind turbine industry: Is there a trade-off between output and innovation capabilities? Global Strategy Journal, 2(3), 205-223.

Bercovitz, J. E., \& Feldman, M. P. (2007). Fishing upstream: Firm innovation strategy and university research alliances. Research Policy, 36(7), 930-948.

Cai, Y. Z., \& Kohtamaki, V. (2014). Transformation of higher education in innovation systems in China and Finland. Filand: Tampere University Press.

Child, J., \& Rodrigues, S. B. (2005). The internationalization of Chinese firms: A case for theoretical extension? Management and Organization Review, 1(3), 381-410.

Deng, P. (2009). Why do Chinese firms tend to acquire strategic assets in international expansion? Journal of World Business, 44(1), 74-84.

Gaffney, N., Cooper, D., Kedia, B., \& Clampit, J. (2014). Institutional transitions, global mindset, and EMNE internationalization. European Management Journal, 32(3), 383-391.

George, G., Zahra, S. A., \& Wood, D. R. (2002). The effects of business-University alliances on innovative output and financial performance: a study of publicly traded biotechnology companies. Journal of Business Venturing, 17(6), 577-609.

Giuliani, E., Gorgoni, S., Günther, C., \& Rabellotti, R. (2014). Emerging versus advanced country MNEs investing in Europe: A typology of subsidiary global-local connections. International Business Review, 23(4), 680-691.

González-Pernía, J. L., Parrilli, M. D., \& Peña-Legazkue, I. (2015). STI—DUI learning modes, firm-university collaboration and innovation. The Journal of Technology Transfer, 40(3), 475-492.

Hong, W., \& Su, Y.-S. (2013). The effect of institutional proximity in non-local university-industry collaborations: An analysis based on Chinese patent data. Research Policy, 42(2), 454-464.

Kedia, B., Gaffney, N., \& Clampit, J. (2012). EMNEs and knowledge-seeking FDI. Management International Review, 52(2), 155-173.

Luo, Y., \& Rui, H. (2009). An ambidexterity perspective toward multinational enterprises from emerging economies. The Academy of Management Perspectives, 23(4), 49-70.

Luo, Y., \& Tung, R. L. (2007). International expansion of emerging market enterprises: A springboard perspective. Journal of International Business Studies, 38(4), 481-498.

Luo, Y., Xue, Q., \& Han, B. (2010). How emerging market governments promote outward FDI: Experience from China. Journal of World Business, 45(1), 68-79.

Madhok, A., \& Keyhani, M. (2012). Acquisitions as entrepreneurship: Asymmetries, opportunities, and the internationalization of multinationals from emerging economies. Global Strategy Journal, 2(1), 26-40.

Mathews, J. A. (2002). Competitive advantages of the latecomer firm: A resource-based account of industrial catch-up strategies. Asia Pacific Journal of Management, 19(4), 467-488.

Milena, Z. R., Dainora, G., \& Alin, S. (2008). Qualitative research methods: A comparison between focus-group and in-depth interview. Annals of the University of Oradea, Economic Science Series, 17(4), 1279-1283.

Mora-Valentin, E. M., Montoro-Sanchez, A., \& Guerras-Martin, L. A. (2004). Determining factors in the success of R\&D cooperative agreements between firms and research organizations. Research Policy, 33(1), 17-40.

Patton, M. Q. (2005). Qualitative research. Wiley Online Library.

Peng, M. W. (2012). The global strategy of emerging multinationals from China. Global Strategy Journal, 2(2), 97-107.

Pillania, R. K. (2009). Multinationals and emerging markets. Business Strategy Series, 10(2), 100-103.

Veugelers, R., \& Cassiman, B. (2005). R\&D cooperation between firms and universities. Some empirical evidence from Belgian manufacturing. International Journal of Industrial Organization, 23(5), 355-379. 